\title{
Study on tensile behaviour of basalt fibre reinforced polymer bars
}

\author{
V. Pavalan ${ }^{1 *}$, I.Thauth Himana ${ }^{2}$ and R. Sivagamasundari ${ }^{3}$ \\ Research Scholar, Department of Structural Engineering, Annamalai University, TamilNadu, India ${ }^{1}$ \\ Research Scholar, Department of Structural Engineering, Annamalai University, TamilNadu, India ${ }^{2}$ \\ Assistant Professor, Department of Structural Engineering, Annamalai University, TamilNadu, India ${ }^{3}$
}

(C2018 ACCENTS

\begin{abstract}
Basalt fibre reinforced polymer bars have emerged as a promising alternative construction material for replacing conventional steel bars as reinforcement in concrete structures. However, a broad research is needed to assess the tensile behaviour of basalt fibre reinforced polymer (BFRP) bars. This paper presents an experimental study on the tensile properties of sand-coated BFRP bars of 8 and $10 \mathrm{~mm}$ - diameters. The tensile specimens of these bars were prepared and tested according to ASTM D7205/D7205M-06. The failure morphologies of BFRP bars were observed with a scanning electron microscopy. The experimental results revealed that BFRP bars have high tensile strength than conventional steel bars but exhibit linear stress-strain relationship up to failure. Moreover, the modulus of elasticity of BFRP bars is significantly lower than that of conventional steel bars.
\end{abstract}

\section{Keywords}

ASTM standards, BFRP bars, Steel bars, Tensile properties, Scanning electron microscopy.

\section{Introduction}

In the last two decades, fibre reinforced polymers (FRPs) have been gradually used in the concrete structures particularly in severe environmental situations as an alternative reinforcement owing to their advantages, e.g., low density, high corrosion resistance and fatigue resistance [1]. Recently, the use of basalt fibre reinforced polymer (BFRP) bars have increased in structural engineering applications due to their low cost compared to other type of FRPs such as Glass, Carbon and Aramid [2, 3]. Moreover, the basalt FRP bars have outstanding chemical stability and excellent resistance to high temperature than glass FRP bars [4]. Basalt fibres are an environmentally safe and nontoxic material as they are made from volcanic rocks without additives [5].

Numerous studies have been found in the literature related to tensile properties of basalt fibre reinforced polymer bars. They revealed BFRP bars are suitable to use in reinforced concrete structures.

Fan et al. [6] investigated the tensile properties of basalt fibre reinforced polymer bars and showed that the ultimate tensile strength of BFRP bars is about three times higher than the ordinary steel bars, and the modulus of elasticity is about $1 / 5$ of the ordinary steel bars.

*Author for correspondence
Huo et al. [7] found that the tensile modulus of elasticity increases with the increase of basalt fibres content when the basalt FRP bars becomes bigger, so the tensile modulus of elasticity increases with the increase of its diameter. Lu et al. [8] experimentally studied the effects of elevated temperatures on basalt fibre roving and pultruded unidirectional BFRP plates. The tensile results of the basalt fibre roving indicated that the temperatures ranging from room temperature to $200^{\circ} \mathrm{C}$ exhibit adverse effects of tensile properties. The tensile strength and modulus of elasticity are reduced by $8.3 \%$ and $9.7 \%$, respectively. On the other hand, the tensile strength and elastic modulus of BFRP plates by $37.5 \%$ and $31 \%$ as temperature rising to $200^{\circ} \mathrm{C}$. Quagliarini et al. [9] studied the tensile characterization of basalt FRP rods and observed that the tested BFRP rods seems to be so rigid but rather deformable and with good ultimate tensile strength. Serbescu et al. [10] tested one thirty two BFRP specimens containing two types and seven different diameters under tension after conditioning in $\mathrm{pH} 9$ and $\mathrm{pH} 13$ solutions at 20, 40 , and $60^{\circ} \mathrm{C}$ for $100 ; 200$ and 1000h. The BFRP bars exhibited an ultimate tensile strength of around $1300 \mathrm{MPa}$, an elastic modulus of $40 \mathrm{GPa}$, and they are evaluated to maintain about $80 \%$ of their ultimate tensile strength after 100 years exposure to concrete and mortar environment, respectively. 
This study focuses on the tensile properties of sandcoated BFRP bars. Further, it clarifies the damage propagation of sand coated BFRP bars under tensile loading through scanning electron microscopy (SEM) analysis.

\section{Materials and experimental procedure 2.1Materials}

The sand-coated BFRP bars of $8 \mathrm{~mm}$ and $10 \mathrm{~mm}$ of diameters provided by Arrow Technical Textiles Private Limited, Mumbai, India was used in this study. The standard epoxy resin (AW-106), hardener (HV-953 IN), steel tubes, steel plugs and PVC caps provided by Malaysia Corporation, Chidambaram, India was used.

\subsection{Specimen preparation}

The tensile specimens were prepared according to the provisions of ASTM D7205/D7205M-06(2011).The total length of the tensile specimen was $1000 \mathrm{~mm}$ and the free length was $400 \mathrm{~mm}$. A $300 \mathrm{~mm}$ - long steel tube anchor with an outside diameter of $25.4 \mathrm{~mm}$ and thickness of $3 \mathrm{~mm}$ was used. Steel Plugs and PVC caps drilled on their centre slightly larger than the bar diameter were used to close at both ends of steel tubes and to insert the bar at the centre of the steel tube. Figure 1 shows the details of the tensile test specimens. The BFRP bars fixed in the steel tubes were placed vertically in a wooden frame for proper alignment. Then the steel tube was filled with mixture of epoxy resin and hardener. After 24 hours, the first anchor was flipped to cast other anchor. The specimen was cured at 7 days in typical indoor laboratory conditions.

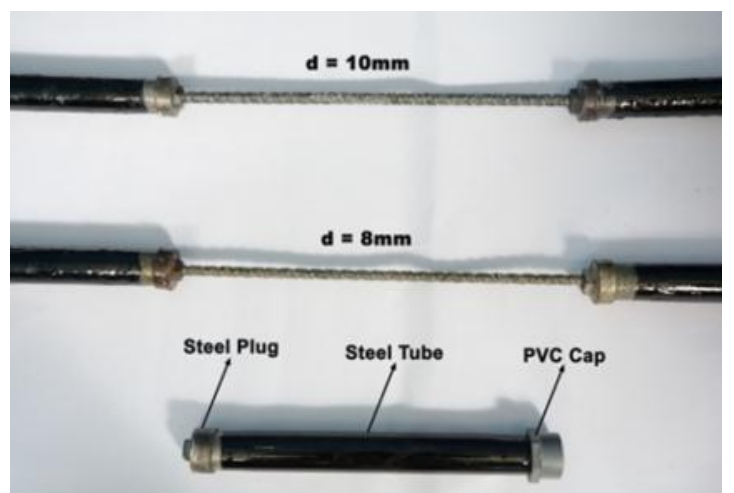

Figure 1 Details of the tensile specimens

\subsection{Test setup}

The tensile tests were carried out by gripping the steel tube into the wedges of MTS testing machine that has a capacity of $1000 \mathrm{kN}$. A loading rate of $250 \mathrm{MPa} / \mathrm{min}$ was used during the test. An extensometer shown in Figure 2 was attached to the BFRP bar to measure strain of the specimen with gauge length of $50 \mathrm{~mm}$. The applied load and BFRP bar extension was electronically recorded by a computerized data acquisition system. The ultimate tensile strength and modulus of elasticity were calculated by using following equations (1) and (2) respectively.

$\mathrm{F}_{\mathrm{tu}}=\mathrm{P}_{\max } / \mathrm{A}$

$\mathrm{E}=\mathrm{P}_{1}-\mathrm{P}_{2} /\left(\varepsilon_{1}-\varepsilon_{2}\right) \mathrm{A}$

Where $F_{t u}$ is ultimate tensile strength (MPa), $P_{\max }$ is the maximum force prior to failure $(\mathrm{N}), \mathrm{A}$ is the crosssectional area of the $\operatorname{bar}\left(\mathrm{mm}^{2}\right)$. E -elastic modulus $(\mathrm{MPa}) ; P_{1^{-}} \quad 50 \%$ maximum $\operatorname{load}(\mathrm{N}) \quad ; P_{2} \quad-20 \%$ maximum load(N)and $\varepsilon_{1}$ the strain corresponding to $50 \%$ of the maximum load; $\varepsilon_{2}$ the strain corresponding to $20 \%$ of the maximum load.

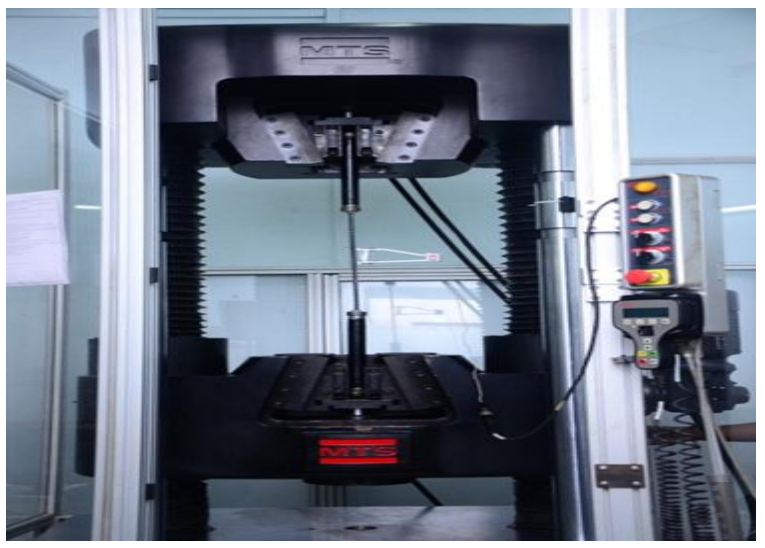

(a)

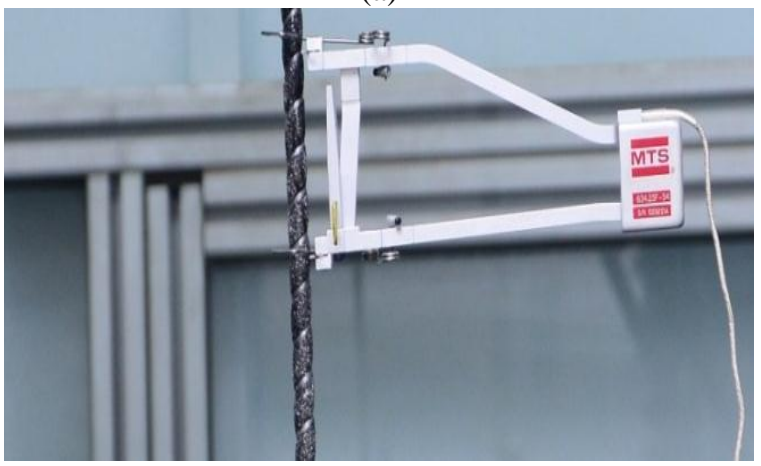

(b)

Figure 2 (a) Tensile test setup (b) Extensometer mounted to the BFRP bar

\section{Results and discussion}

\subsection{Tensile test}

The ultimate tensile strength and modulus of elasticity of BFRP and conventional steel bars were tabulated in Table 1. All of the BFRP specimens 
Pavalan et al.

failed in the free length through the rupture of fibres as shown in Figure 3. According to the test results, the ultimate tensile strength of the BFRP bars was 3 times higher than that of conventional steel bars, and the modulus of elasticity was about $1 / 4$ of the conventional steel bars. The stress-strain relationship of the BFRP bars is linear, does not have any yield point up to the failure (Figure 5). After tensile testing, the steel tube anchors of the specimens were cut through saw blade at both ends to notice the condition of the BFRP bars [11]. Figure 4 shows the some exposed fibres at end of the BFRP bar. Clearly, the sand coating at the BFRP bar ends was not damaged.

Table 1 Tensile properties of BFRP and conventional steel bars

\begin{tabular}{lllll}
\hline Specimen Id & $\begin{array}{l}\text { Peak tensile } \\
\text { load [kN] }\end{array}$ & $\begin{array}{l}\text { Peak tensile } \\
\text { extension [mm] }\end{array}$ & $\begin{array}{l}\text { Ultimate } \\
\text { strength [MPa] }\end{array}$ & $\begin{array}{l}\text { Elastic } \\
\text { modulus [GPa] }\end{array}$ \\
\hline BFRP-8-1 & 70.2 & 20.1 & 1396.5 & 49.5 \\
BFRP-8-2 & 68.3 & 19.4 & 1358.7 & 48 \\
BFRP-8-3 & 69.7 & 19.8 & 1386.5 & 49.4 \\
BFRP-8-4 & 69.5 & 19.7 & 1382.5 & 48.7 \\
BFRP-8-5 & 69.6 & 19.5 & 1364.6 & 48.6 \\
BFRP-10-1 & 114.8 & 38.9 & 1461.6 & 50.3 \\
BFRP-10-2 & 116.2 & 40.3 & 1479.5 & 50 \\
BFRP-10-3 & 115.7 & 39.3 & 1473.1 & 50.6 \\
BFRP-10-4 & 117.1 & 40.4 & 1490.8 & 50.9 \\
BFRP-10-5 & 115.2 & 39.3 & 1470.7 & 50 \\
STEEl-10 & 45.3 & 36.8 & 587.6 & 200 \\
\hline
\end{tabular}

According to the Specifications of the ASTM D7205/D7205M-06, for each series of tests were calculated the average, Standard deviation and coefficient of variation using the following expressions 3 to 5.The coefficient of variation valves of sand-coated BFRP bars of $8 \mathrm{~mm}$ and $10 \mathrm{~mm}-$ diameters were relatively small, less than $1 \%$ for these cases.

$$
\begin{aligned}
& \bar{x}=\left(\sum_{i=1}^{n} x_{i}\right) / n \\
& S_{n-1}=\sqrt{\left.\sum_{i=1}^{n} x_{i}^{2}-n \bar{x}\right) /(n-1)} \\
& C V=1-\left(S_{n-1} / \bar{x}\right)
\end{aligned}
$$

Where $\bar{x}=$ mean; $\mathrm{S}_{\mathrm{n}-1}=$ standard deviation; $\mathrm{CV}=$ coefficient of variation; $\mathrm{n}=$ number of tested specimens; $\mathrm{x}_{1}=$ measured or derived property. Table 2 shows the Statistical analysis.

Table 2 Statistical analysis

\begin{tabular}{cccc}
\hline $\begin{array}{c}\text { Type of } \\
\text { specimen }\end{array}$ & $\begin{array}{c}\text { Mean } \\
(\mathbf{M P a})\end{array}$ & $\begin{array}{c}\text { Standard } \\
\text { deviation } \\
(\mathbf{M P a})\end{array}$ & $\begin{array}{c}\text { Coefficient of } \\
\text { variation }(\%)\end{array}$ \\
\hline BFRP8 & 1377.8 & 15.70 & 0.99 \\
BFRP10 & 1475.1 & 16.29 & 0.89 \\
\hline
\end{tabular}

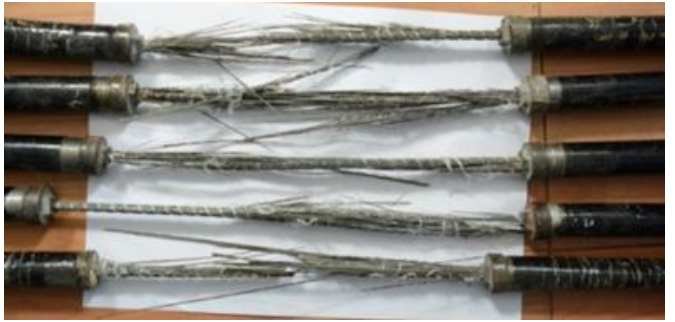

Figure 3 Failure of tensile specimens
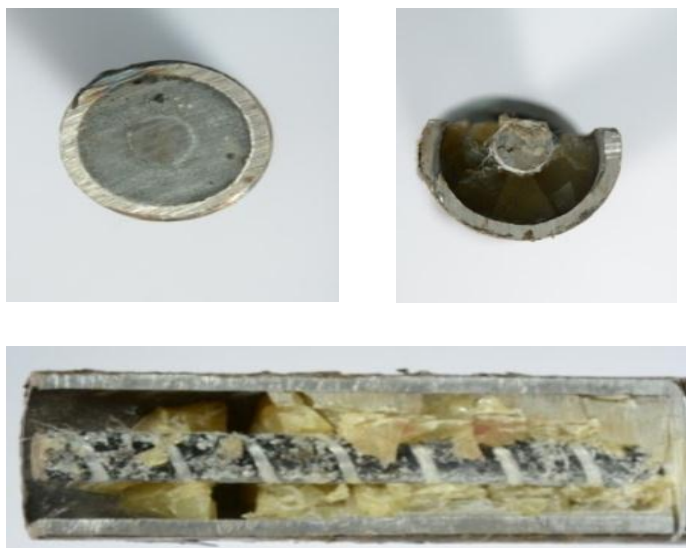

Figure 4 BFRP bar ends in the steel tube anchors after tensile test 


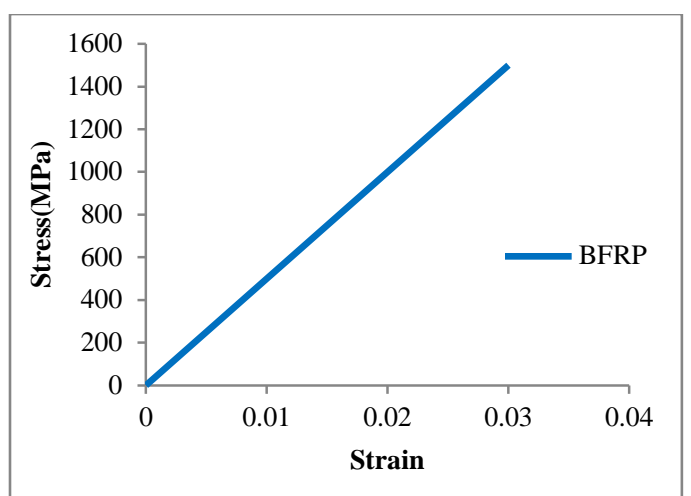

Figure 5 Stress-strain response of tested BFRP specimens

3.2Scanning electron microscopy (SEM) analysis Scanning Electron Microscopy (SEM) analysis is used to observe the surface morphologies of fibres and fractured surface of fibre composites. The tensile fracture surfaces of the BFRP specimens at different magnifications are presented in Figure 6. The breakage of the basalt fibre is clearly visible in the SEM image due to tensile loading. The images have similar trend with published results $[12,13]$.
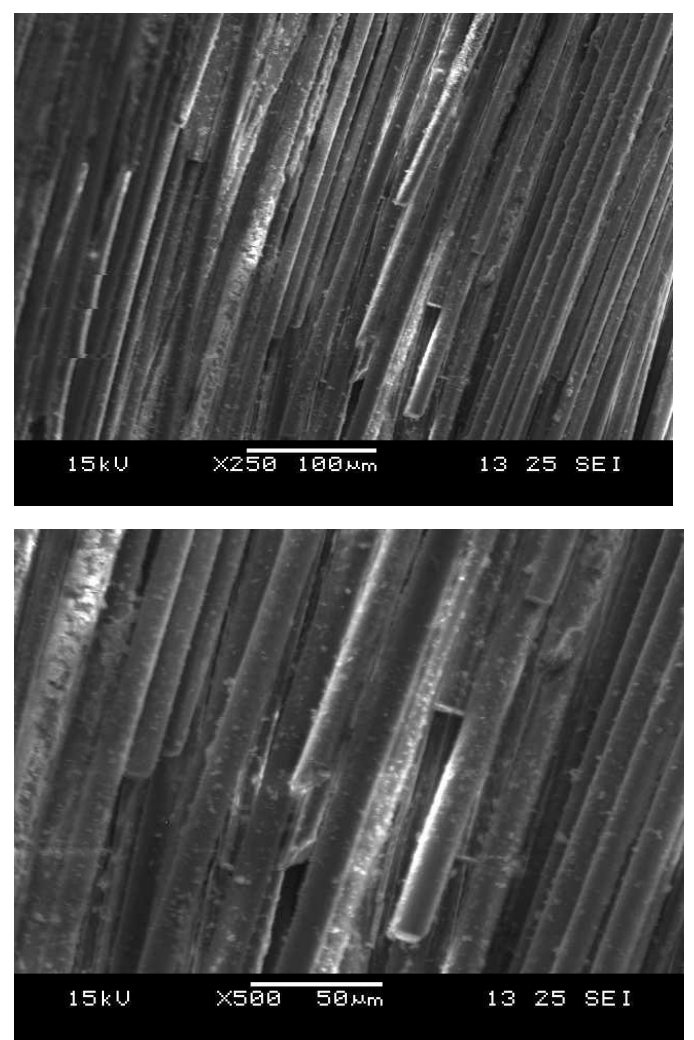

Figure 6 SEM images of the tensile fracture surfaces of BFRP specimens

\section{Conclusion}

In the present paper, the tensile properties of the sand-coated BFRP bars were investigated. The SEM analysis was performed to observe the internal surface of the fractured specimen. The following conclusions were drawn from the experimental results. The ultimate tensile strength of the BFRP bars was 3 times higher than that of conventional steel bars, and the modulus of elasticity was about $1 / 4$ of the conventional steel bars. The stress-strain relationship of the BFRP bars is linear, does not have any yield point up to the failure. The fractured surfaces and fibre failure mode of the tested BFRP specimens were clearly noticed from the morphological observations.

\section{Acknowledgment}

None.

\section{Conflicts of interest}

The authors have no conflicts of interest to declare.

\section{References}

[1] Micelli F, Nanni A. Tensile characterization of FRP rods for reinforced concrete structures. Mechanics of Composite Materials. 2003; 39(4):293-304.

[2] Sim J, Park C. Characteristics of basalt fiber as a strengthening material for concrete structures. Composites Part B: Engineering. 2005; 36(6-7):50412.

[3] Wei B, Cao H, Song S. Tensile behavior contrast of basalt and glass fibers after chemical treatment. Materials \& Design. 2010; 31(9):4244-50.

[4] Hwang JH, Seo DW, Park KT, You YJ. Experimental study on the mechanical properties of FRP bars by hybridizing with steel wires. Engineering. 2014; 6(7):365-73.

[5] Kocaoz S, Samaranayake VA, Nanni A. Tensile characterization of glass FRP bars. Composites Part B: Engineering. 2005; 36(2):127-34.

[6] Fan X, Xu T, Zhou Z, Zhou X. Experimental study on basic mechanical properties of BFRP Bars. In IOP conference series: materials science and engineering 2017 (pp. 1-6). IOP Publishing.

[7] Huo BR, Zhang XD. Experiment study of BFRP bars' mechanical properties. In Applied Mechanics and Materials 2012; 174:830-3. Trans Tech Publications.

[8] Lu Z, Xian G, Li H. Experimental study on the mechanical properties of basalt fibres and pultruded BFRP plates at elevated temperatures. Polymers \& Polymer Composites. 2015; 23(5):277-83.

[9] Quagliarini E, Monni F, Lenci S, Bondioli F. Tensile characterization of basalt fiber rods and ropes: a first contribution. Construction and Building Materials. 2012; 34:372-80.

[10] Serbescu A, Guadagnini M, Pilakoutas K. Mechanical characterization of basalt FRP rebars and long-term 
Pavalan et al.

strength predictive model. Journal of Composites for Construction. 2014; 19(2).

[11] Benmokrane B, Nazair C, Seynave X, Manalo A. Comparison between ASTM D7205 and CSA S806 tensile-testing methods for glass fiber-reinforced polymer bars. Journal of Composites for Construction. 2017; 21(5).

[12] Manikandan V, Jappes JW, Kumar SS, Amuthakkannan P. Investigation of the effect of surface modifications on the mechanical properties of basalt fibre reinforced polymer composites. Composites Part B: Engineering. 2012; 43(2):812-8.

[13] Lu Z, Xian G, Li H. Effects of elevated temperatures on the mechanical properties of basalt fibers and BFRP plates. Construction and Building Materials. 2016; 127:1029-36.

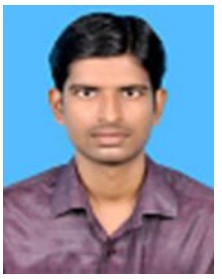

Pavalan Veerapandian was born in 1991.He received his Master degree in the Department of Civil \& Structural Engineering, Annamalai University in 2014.At present, he is pursuing Ph.D degree in Structural Engineering, Annamalai University.He published two articles in International journal of civil engineering \& technology and International journal of emerging technology and advanced engineering.

Email: Pavalan91@gmail.com 